\title{
Complications in endoscopic retrograde cholangiopancreatography (ERCP) and endoscopic ultrasound (EUS): analysis of 7-year physician-reported adverse events
}

\author{
This article was published in the following Dove Press journal: \\ Drug, Healthcare and Patient Safety \\ 20 June 2011 \\ Number of times this article has been viewed
}

\author{
Yaron Niv' \\ Yael Gershtansky² \\ Ron S Kenett ${ }^{3}$ \\ Yossi Tal ${ }^{2}$ \\ Shlomo Birkenfeld ${ }^{4}$ \\ 'Department of Gastroenterology, \\ Rabin Medical Center, Petach Tikva, \\ Israel; ${ }^{2}$ Medical Risk Management, \\ The Madanes Group, Tel Aviv, Israel; \\ ${ }^{3}$ The KPA Group, University of Torino, \\ Turin, Italy; ${ }^{4} \mathrm{Clalit}$ Health Services, \\ Tel Aviv, Israel
}

\begin{abstract}
Introduction: The number of malpractice claims against physicians and health institutes is increasing continuously in Israel as in the rest of the Western world, and has become a serious financial burden.

Aim: In this study we analyzed the reports of gastroenterologists on endoscopic retrograde cholangiopancreatography (ERCP) and endoscopic ultrasound (EUS) adverse events to the risk management authority between January 1, 2000 and December 31, 2006.

Methods: All the reported adverse events associated with ERCP and EUS of health institutes and covered by Madanes Insurance Agency were summarized and analyzed. Clinical and epidemiological details about the patients, procedures, and adverse events were coded into an Excel worksheet, discussed, and evaluated.

Results: Forty-two cases of ERCP and EUS adverse events were reported. There were nine cases of men (21.4\%) and the average age was $69.3 \pm 14.3$ years. During this period, 10,647 procedures were performed by the institutes concerned and the number of adverse events was 20.2 to 67.8 per year for 10,000 procedures. Perforation occurred in one out of 367 procedures, bleeding in one out of 5323 procedures, teeth trauma in one out of 5323 procedures, and respiratory complications in one out of 10,647 procedures.

Conclusion: This is the first study in Israel about physicians' reports of ERCP and EUS adverse events. Physicians reported only about severe adverse events with high rate of mortality and morbidity.
\end{abstract}

Keywords: ERCP, EUS, defensive medicine, perforation, bleeding, sedation, risk management, patient safety

\section{Introduction}

More than $60 \%$ of the Israeli population has a mandatory health insurance by Clalit Health Services (CHS). The physicians of CHS, in the community as well as in hospitals, have malpractice insurance at the same company. The number of malpractice claims against physicians and health institutions is increasing continuously in Israel as in the rest of the Western world, and has become a serious financial burden. Health economy has become critically unstable, and strategies for decreasing claims and reducing losses have become an integral part of every health plan in Israel. It was recently reported that $93 \%$ and $98 \%$ of American and Japanese physicians, respectively, practice defensive medicine, such as assurance behavior, as well as avoidance behavior. $^{1,2}$ 
Health organizations in Israel demand an immediate report of any error or complication in patients' management. The report provides the insurer with an opportunity to prepare the defense for a potential claim, and to discuss the case when a personal or system failure is suspected. Sometimes physicians are reluctant to report errors, facing a self-image or ego conflict, as well as peer and managerial criticism. Intensive persuasive efforts of health organizations claiming that early reports are for the physician's own benefit, gradually overcome this problem and regular reporting increasingly approaches the rate of real life events. Still, significant under-reporting of medical complications is evident.

In this study, we analyzed the reports of CHS gastroenterologists on endoscopic retrograde cholangiopancreatography (ERCP) and endoscopic ultrasound (EUS) adverse events to the Risk Management Authority, between January 1, 2000 and December 31, 2006. We aimed to characterize reports of errors or complications in patients' management by gastroenterologists performing ERCP and EUS for evaluation of bile duct and pancreatic diseases. Our paper is by all means not a review of procedure complications.

\section{Methods}

All the reports of physicians associated with ERCP and EUS adverse events or complications from health institutes covered by Madanes Insurance Company between January 1, 2000 and December 31, 2006 were summarized by the authors during several meetings. Clinical and epidemiological details about the patients, procedure, and adverse events were coded into an Excel worksheet, discussed, and evaluated by all four researchers. Date, time of the day and place of the procedure, background diseases and operations, medications, indication, additional procedure such as sphincterotomy, dilatation, and biopsy, completeness of informed consent, treatment with anticoagulant or anti platelets adhesion agent, adverse events and the time of diagnosis, and treatment of complication and outcome were all thoroughly discussed and computed. The number of procedures performed for the members of CHS in Israel between 2000 and 2006 was extracted from the CHS database for each year of the study. The incidence of ERCP and EUS adverse events was separately calculated for members of CHS according to the database for this period.

A quantum $(Q)$ value, a parameter for a potential claim and its value in Israeli shekels, was calculated for each case, and assigned zero (no potential claim) or > zero (potential claim). Parameters that have impact on the $Q$ value are: severity of complication, pain, suffering, decrease in the ability to work and salary (in relationship to income and family status), need of help for daily activity, potential changes in housing or relocation, life expectancy, expenses in the particular case, and experience with similar cases in the past.

Statistical analysis was performed using SPSS (v 13; IBM, Petach Tikva, Israel). The results are expressed as mean \pm standard deviation; $P<0.05$ were considered significant. Kruskal-Wallis, Mann-Whitney, Chi-square, and ANOVA tests were used as needed.

\section{Results}

Forty-two cases of ERCP and EUS adverse events were reported to Madanes Insurance Company between January 1, 2000 and December 31, 2006; 38 cases (90.5\%) of them belong to CHS. Clinical and demographic data of the cases are presented in Table 1 . There were nine cases of men $(21.4 \%)$ and the average age was $69.3 \pm 14.3$ years, range $7-87$ years, median 71 years. Thirty-four patients $(80.9 \%)$ were 65 years or older. Thirty-five events $(83.3 \%)$ were reported voluntarily by the staff (primary report), and seven (16.7\%) were reported after a claim was submitted (secondary report). Most of the procedures were for therapeutic reasons and performed on an elective basis. More than $50 \%$ of the patients had two or more chronic background diseases, had undergone two

Table I Demographic and clinical data of the reported cases, $N=42$ (100\%)

\begin{tabular}{|c|c|c|}
\hline Parameter & $\mathbf{N}$ & $\%$ \\
\hline \multicolumn{3}{|l|}{ Sex } \\
\hline Men & 9 & 21.4 \\
\hline Women & 33 & 78.6 \\
\hline \multicolumn{3}{|l|}{ Age } \\
\hline Average \pm standard deviation $(y)$ & $69.3 \pm 14.3$ & \\
\hline Median (y) & 71 & \\
\hline Range (y) & $7-87$ & \\
\hline$>65$ years & 34 & 80.9 \\
\hline \multicolumn{3}{|l|}{ Referral center } \\
\hline Hospital & 41 & 97.6 \\
\hline Community unit & I & 2.4 \\
\hline \multicolumn{3}{|l|}{ State of urgency } \\
\hline Elective & 23 & 54.8 \\
\hline Urgent & 19 & 45.2 \\
\hline \multicolumn{3}{|l|}{ Procedure characteristics } \\
\hline Diagnostic ERCP & 8 & 19.0 \\
\hline Therapeutic ERCP & 27 & 64.3 \\
\hline EUS & 7 & 16.7 \\
\hline Record of two or more chronic diseases & 21 & 50.0 \\
\hline Record of two or more operations & 31 & 73.8 \\
\hline Record of two or more medications & 30 & 71.4 \\
\hline \multicolumn{3}{|l|}{ Anticoagulant or antiplatelet therapy } \\
\hline None & 22 & 52.4 \\
\hline Aspirin & 14 & 33.3 \\
\hline Coumadin & $\mathrm{I}$ & 2.4 \\
\hline Unknown & 5 & 11.9 \\
\hline
\end{tabular}


or more operations, and were regularly treated with two or more medications, including aspirin (33.3\%) and coumadin $(2.4 \%)$.

Distribution of the ERCP and EUS adverse events during a 7-year period for CHS members is demonstrated in Table 2. During this period, 10,647 ERCP and EUS were performed by the institutes concerned. The number of adverse events was between 20.2 and 67.8 per year for 10,000 procedures. The difference between the years was not statistically significant. Perforation occurred in one out of 367 procedures, bleeding in one out of 5323 procedures, teeth trauma in one out of 5323 procedures, and respiratory complications in one out of 10,647 procedures.

Distribution of the adverse events along the week working days was between $11.9 \%$ minimum and $42.9 \%$ maximum on Monday and Thursday, respectively. Thirty-two events (76.2\%) occurred in the morning and two (4.8\%) in the afternoon. Informed consent was properly filled and signed in 30 cases $(71.4 \%)$, and partially filled in three additional cases $(7.1 \%)$. The informed consent form could not be found in the patients files in nine cases $(21.4 \%)$.

Description of adverse events and clinical outcome is demonstrated in Table 3. There were 29 perforations, $69 \%$ of the adverse events. Most of the cases were detected and reported immediately or within 24 hours. The 29 patients were operated upon (69\%), but all required hospitalization. The majority of the involved patients suffered critical outcomes: 15 mortality cases $(35.7 \%)$ and 18 patients $(42.9 \%)$ had residual damage.

The status of legal claims is presented in Table 4. Only a minority of the cases was debated in court; seven ended with compromise agreements and two are engaged in ongoing negotiations.

The Q value was zero in 13 cases (31\%), and 100,000 or higher in seven cases (16.6\%); mean $=50,022 \pm 93,478$, median $=20,000$, and range 0-54,023 new Israeli Shekel (NIS).

Table 2 Distribution of ERCP and EUS adverse events during 7-year period for CHS members

\begin{tabular}{llll}
\hline Year & $\begin{array}{l}\text { Number of } \\
\text { adverse } \\
\text { events }\end{array}$ & $\begin{array}{l}\text { Number of } \\
\text { procedures } \\
\text { performed }\end{array}$ & $\begin{array}{l}\text { Number of adverse } \\
\text { events per 10,000 } \\
\text { procedures }\end{array}$ \\
\hline 2000 & 5 & 883 & 56.6 \\
2001 & 4 & 964 & 41.5 \\
2002 & 13 & 1917 & 67.8 \\
2003 & 4 & 1972 & 20.2 \\
2004 & 5 & 1986 & 25.2 \\
2005 & 4 & 1583 & 25.3 \\
2006 & 7 & 1342 & 52.2 \\
Total & 42 & 10,647 & 39.5 \\
\hline
\end{tabular}

Table 3 Adverse events in ERCP and EUS, N = 42 (I00\%)

\begin{tabular}{lll}
\hline Parameter & N & $\%$ \\
\hline Complication & 29 & \\
Perforation & 2 & 69.0 \\
Bleeding & 1 & 4.8 \\
Cardiovascular and respiratory event & 2 & 4.8 \\
Teeth trauma & 2.4 \\
Other & 8 & 19.0 \\
Time detected & & \\
Immediately & 23 & 54.8 \\
Within 24 hours & 13 & 31.0 \\
More than 24 hours & 3 & 7.1 \\
Unknown & 3 & 7.1 \\
Treatment & & \\
Operation & 29 & 69.0 \\
Hospitalization and conservative treatment & 7 & 16.7 \\
Ambulatory treatment & 4 & 9.6 \\
Unknown & 2 & 4.7 \\
Outcome & & \\
Residual damage & 18 & 42.9 \\
Complete healing & 6 & 14.3 \\
Death & 15 & 35.7 \\
Unknown & 3 & 7.1 \\
\hline
\end{tabular}

\section{Discussion}

Reporting adverse events and complications is part of daily routine work in Israeli medicine encouraged by the health organizations and the insurance companies, but not supported by objective measures. ${ }^{3}$ With sensational mass media reporting on medical malpractice, physicians have begun to focus on risk management activities leading them to practice defensive medicine. This strategy enables preparation for potential claims, collecting specific data, assigning dedicated sums of money by the insurance company, and also collecting data for the purpose of quality assurance measurements.

Described adverse events and complications of ERCP and EUS included perforation, bleeding, sedation associated cardiovascular and respiratory problems, and missing or misinterpreting lesions. ${ }^{4}$

The manner in which the incident is handled has important consequences for the affected patients' decision to take legal action. ${ }^{5,6}$ Complete disclosure of adverse event or near-miss situations to the patients and family members

Table 4 Claims and legal status for July 16, 2010

\begin{tabular}{lll}
\hline Parameter & N & $\%$ \\
\hline Court litigation & 2 & 4.8 \\
Compromise agreement & 7 & 16.6 \\
Limitation & II & 26.2 \\
Other & 22 & 52.4 \\
\hline
\end{tabular}


may prevent lawsuits, but this strategy is not always practiced because of shame, embarrassment, fear of losing trust, and lack of training. ${ }^{7-10}$

The most important complication of ERCP and EUS is perforation. The incidence of perforation is estimated to be $0.5 \% .{ }^{4}$ In our reported series, it ranges from $0.075 \%$ following diagnostic procedures to $0.25 \%$ following interventions.

In the present paper, we described 42 cases of adverse events during ERCP and EUS reported to the Madanes Insurance Company in a 7-year period. Not surprisingly, most of the cases were of elderly patients with a background of chronic diseases. The rate of perforation was well within the accepted range described in the literature, and most of them happened in therapeutic procedures. The rarity of respiratory and cardiovascular complication, most probably due to sedation, is outstanding. Only one case was reported, thus a ratio of one in 10,647 procedures could be calculated. The clinical outcome was not so favorable. There were 15 cases of mortality and 29 patients underwent operation. Eighteen patients were left with residual damage.

Most of the complications were diagnosed early, 54.8\% immediately after the procedure and an additional $31 \%$ within 24 hours. In 13 cases the Q value was zero and no further legal evaluation should be performed, while in seven cases the Q value was 100,000 and higher, and these cases were evaluated thoroughly for potential litigations and financial compensation.

It is not possible to estimate the true rate of adverse events according to these voluntary reports. We believe that there are far more cases than reported. Milch et al analyzed 92,547 reports from 26 acute care hospitals and found a wide reporting rate difference across hospitals, nine to 95 reports per 1,000 inpatient-days (median $=35) .{ }^{9}$ Thus, reporting should be improved. Vincent et al described four main reasons for litigation: concern with standard of care, the need for explanation, compensation, and accountability. ${ }^{10}$ Reporting adverse events is an essential component in the training of staff and organizations that should have to account for their actions. In a survey of teaching hospitals, Kaldjian et al demonstrated that most faculty and resident physicians are inclined to report harm-causing hypothetical errors, but only a minority has actually reported an error. ${ }^{8}$

Being an insurance company, Madanes receives reports that are basically major events with evident damage to the patient, ie, the probability of a claim is fairly high. When analyzing the events in our cohort we observed the phenomenon that almost $80 \%$ of the reported events resulted in death of the patient or residual damage.
According to Heinrich's Iceberg model, ${ }^{8}$ for each severe accident there are 29 accidents with minor damages and 300 accidents with marginal damages or without damages at all. It may be calculated that the real numbers of adverse events in the analyzed 7-year period should be as follows: 33 reported adverse events involving fatality or residual damage, 957 adverse events with minor damages, and 9900 adverse events with marginal damage or no damage at all - "near misses". We can assume that in this article we analyzed the tip of the iceberg assuming that the insured institutions reported the severe occurrences to the insurer and avoided reporting the less severe occurrences. Kern investigated 99 malpractice cases that came to trial in the United States federal and state civil court system, involving 103 allegations of negligence over a 21 -year period. ${ }^{12}$ There were 44 cases of misdiagnosis, 25 cases of iatrogenic injury, and 16 cases of medical complication. In eight cases $(8 \%)$, lack of informed consent was the reason for litigation. This series is different from our cohort, where misdiagnosis was not part of it.

Our study is limited by being retrospective and by a lack of essential data from the patients' files and source documents. In addition, the follow-up is too short to evaluate the legal outcome of this cohort. We do not have information about the number of patients that still can sue or complain. This paper is about "physicians' reports", and should be accepted as such. One should learn about reporting habits of gastroenterologists performing EUS and ERCP from our data, and not to assess the safety of the procedures.

\section{Conclusion}

This is the first study in Israel about physicians' reports of ERCP and EUS adverse events. Physicians only reported severe adverse events with a high rate of mortality and morbidity.

\section{Disclosure}

The authors report no conflicts of interest in this work.

\section{References}

1. Studdert DM, Mello MM, Sage WM, et al. Defensive medicine among high-risk specialist physicians in a volatile malpractice environment. JAMA. 2005;293(21):2609-2617.

2. Hiyama T, Yoshihara M, Tanaka S, et al. Defensive medicine practices among gastroenterologists in Japan. World J Gastroenterol. 2006; 12(47):7671-7675.

3. Glassman PA, Rolph JE, Peterson LP, Bradley MA, Kravitz RL. Physicians' personal malpractice experiences are not related to defensive clinical practices. J Health Polit Policy Law. 1996;21(2):219-241.

4. Kimmey MB. Complication of gastrointestinal endoscopy. In: Feldman M, Friedman LS, Brandt LJ, editors. Sleisenger and Fordtran's Gastrointestinal and Liver Disease. 9th ed. Philadelphia, PA: Saunders \& Elsevier; 2010:653-661. 
5. Wu AW. Handling hospital errors: is disclosure the best defense? Ann Intern Med. 1999;131(12):970-972.

6. Gallagher TH, Waterman AD, Ebers AG, Fraser VJ, Levinson W. Patients' and physicians' attitudes regarding the disclosure of medical errors. JAMA. 2003;289(8):1001-1007.

7. Hingorani M, Wong T, Vafidis G. Patients' and doctors' attitudes to amount of information given after unintended injury during treatment cross sectional, questionnaire survey. BMJ. 1999;318(7184):640-641.

8. Kaldjian LC, Jones EW, Wu BJ, Forman-Hoffman VL, Levi BH, Rosenthal GE. Reporting medical errors to improve patient safety: a survey of physicians in teaching hospitals. Arch Intern Med. 2008;168(1): $40-46$.
9. Milch CE, Salem DN, Pauker SG, Lundquist TG, Kumar S, Chen J. Voluntary electronic reporting of medical errors and adverse events. An analysis of 92,547 reports from 26 acute care hospitals. J Gen Intern Med. 2006;21(2):165-170.

10. Vincent C, Young M, Phillips A. Why do people sue doctors? a study of patients and relatives taking legal action. Lancet. 1994;343(8913): 1609-1613.

11. Heinrich HW. Industrial accident prevention. A scientific approach. New York and London, UK: McGraw-Hill Insurance Series; 1931.

12. Kern KA. Medical malpractice involving colon and rectal disease: a 20-year review of United States civil court litigation. Dis Colon Rectum. 1993;36(6):531-539.

\section{Publish your work in this journal}

Drug, Healthcare and Patient Safety is an international, peer-reviewed open-access journal exploring patient safety issues in the healthcare continuum from diagnostic and screening interventions through to treatment, drug therapy and surgery. The journal is characterized by the rapic reporting of reviews, original research, clinical, epidemiological and

\section{Dovepress}

post-marketing surveillance studies, risk management, health literacy and educational programs across all areas of healthcare delivery. The manuscript management system is completely online and includes a very quick and fair peer-review system. Visit http://www.dovepress.com/ testimonials.php to read real quotes from published authors.

Submit your manuscript here: http://www.dovepress.com/drug-healthcare-and-patient-safety-journal 